\title{
Kısa süreli endotrakeal entübasyonun ses kalitesi ve aralığına etkisi
}

\section{The effect of short term endotracheal intubation on voice quality and range}

\author{
Ceki Paltura, Gülşah Acar Yüceant
}

Sağlık Bilimleri Üniversitesi Haseki Eğitim ve Araştırma Hastanesi, Kulak Burun Boğaz Kliniği, İstanbul, Turkey

\section{Özet}

Amaç: Kısa süreli Endotrakeal Entübasyon (EE) sonucu oluşan vokal kord hasarının ses kalitesi ve ses aralığına olan etkisi incelenmiştir.

Gereç ve Yöntem: Araştırma Sağlık Bakanlığı Üniversitesi Haseki Eğitim ve Araştırma Hastanesi KBB Kliniği'nde yürütüldü. Hastaların ameliyat öncesi ses kayıtları alındı. Hastaların aralıkları hesaplandı. Ölçümler postoperatif 24. saatte tekrarlandı. Sonuçlar istatistiksel olarak karşılaştırıldı.

Bulgular: Çalışmaya 24'ü (\%60) kadın, 16'ı (\%40) erkek 40 hasta dahil edildi. Hastaların yaş ortalaması 33.70 (17-55) idi. Hastaların operasyon sonrasındaki Bazal Frekans (F0) değerlerinin, en tiz ses frekansının ve ses aralıklarının operasyon öncesi değerlere göre istatistiksel olarak anlamlı olarak daha az olduğu saptanmıştır. Jitter, Shimmer ve Harmonik-Gürültü oranında ise anlamlı değişiklik saptanmamıştır.

Sonuç: EE'un invaziv bir girişim olması nedeni ile vokal kordlar üzerinde belli etkileri olmaktadır. Bu etkiler genelde kısa sürede gerilemektedir. Ses profesyonellerinin bu dönemde seslerini daha güvenli kullanmaları önerilmektedir.

Anahtar Sözcükler: Endotrakeal entübasyon; vokal kord hasarı.

A nestezi derinleştikten sonra hastanın solunumunu ameliyat süresince kontrol etmek ve anestezinin etkinliğinin takibi için Endotrakeal Entübasyon (EE) işlemi yapılmaktadır. Friedrich Trandelenburg bu işlemi 1869 yllında trakeostomi kanülünü kullanarak yapmıştır. ${ }^{[1]}$ illk EE MacEven tarafından yapılmış olup, Edgar Rowbotham ve Ivan Magill 1. Dünya Savaşı'nda bu yöntemi kullanıp popülerize etmiştir. ${ }^{[2]} 20$. yüzyılın ikinci yarısında teknolojinin de gelişmesi günümüzde anestezinin vazgeçilmez bir parçası olarak yerini almıştır. EE işlemi girişimsel bir işlemdir. Endotrakeal tübün uygun yerine yerleş-

\begin{abstract}
Introduction: To evaluate the voice quality and range after vocal fold trauma due to Endotracheal Intubation (El).

Methods: The research had been processed in Ministry of Health University Haseki Education and Research Hospital Otolaryngology Head and Neck Clinic. The voice samples of patients were recorded preoperatively. The voice ranges of patients were calculated. The recordings were repeated at $24 \mathrm{~h}$ after operation. The results were statistically compared.

Results: The research was undergone with 24 (60\%) female, 16 (40\%) male, total 40 patients. The mean age was 33.70 (17-55). Postoperative acoustic analysis revealed that the fundamental frequency (FO), highest level of voice and vocal range were a statistically significant decreased from preoperative levels. Jitter, Shimmer and Harmonic-toNoise ratios did not changed significantly.

Discussion and Conclusion: The El is an invasive process and has some effects on vocal cords. These effects usisally resolve in a short time. The voice professionals need to use their voice more precautiously during this period.

Keywords: Endotracheal entubation; vocal cord injury.
\end{abstract}

tirilmesi sırasında ya da uzun süreli kullanımına bağlı olarak larenks ve trakeada hasar oluşabilir.

$E E^{\prime} y e$ bağlı erken dönemde postentübasyon ülseri, aritenoid dislokasyonu, vokal proçes granülomu ve rekürren laringeal sinir parezisi gibi problemler gözlenmiş ve birçok çalışmada incelenmiştir. ${ }^{[3,4]}$ Larenks muayenesi ile saptanabilen bu lezyonlar haricinde birçok hastanın ameliyat sonrasında boğaz ağrısı, yutkunma problemleri ve ses kısıklığı gibi şikayetleri olmaktadır. Genelde 24-72 saat içinde gerileyen bu şikayetler 
hastadan hastaya değişiklik gösterir. ${ }^{[5]}$ Şikayetlerin kısa süreli olması ve kalıcı hasar bırakmaması nedeni ile çoğu kez hem hekim hem de hasta tarafından göz ardı edilir. Ancak ses profesyonelleri olarak adlandırılan hastalarda, ses kısıklığı olması ciddi problemlere neden olabilir. Bu nedenle bu dönemde ses kalitesinde olabilecek değişiklikleri bilmek ve hastalara bunlarla ilgili gerekli bilgileri vermemiz gerekmektedir.

Bu çalışmada 1 saati aşmayan EE sonrasında ses kalite parametrelerinin nasıl değiştiğini ve özellikle ses aralığında bir değişiklik olup olmadığını inceledik.

\section{Gereç ve Yöntem}

Araştırma İstanbul Haseki Eğitim ve Araştırma Hastanesi KBB Kliniği'nde yürütülmüştür. Araştırma için aynı hastanenin etik kurulundan onay alınmıştır (178/28.01.2015). Çalışmaya Haseki Hastanesi KBB Kliniği'nde ameliyat olan hastalar dahil edilmiştir. Hastalar ameliyat öncesinde yapılacak çalışma hakkında bilgilendirilmiş ve onamları alınmıştır. Çalışmaya KBB Kliniğinde ameliyat olan 40 hasta dahil edilmiştir. Çalışmaya ses kalitesini etkileyebilecek bir cerrahi geçiren (üst hava yolu cerrahisi, abdomen ya da toraks cerrahisi gibi), sigara içen, kronik bir hastalığı olan (diyabetes mellitus, hipertansiyon, astım, kronik obstrüktif akciğer hastalığı veya astım gibi) ya da daha önce vokal korddaki bir patoloji nedeni ile ameliyat olan ve ameliyatı 1 saatten daha uzun süren hastalar dahil edilmemiştir. Hastaların ameliyat süreleri ve uygulanan ilaçlar standardize edildi. Hastalar aynı anestezi hekimi tarafından ve tek seferde entübe edildi.

Hastaların ameliyat öncesinde ve 24 saat sonrasında ses yalıtımının yapıldığı bir ortamda ses kaydı ve ölçümleri yapıldı. Hastaların ses kaydına ortamın kalibrasyonu ile başlandı. Mikrofon (Audio-Technica AT2005USB Cardioid Dynamic USB/XLR Microphone, Audio-Technica U.S., Inc.) hastanın ağzından $5 \mathrm{~cm}$ uzakta tutularak hastalardan /a/ sesini en rahat kullandıkları ses perdesi ve yükseklikte 5 sn boyunca çıkarması istendi. Mikrofonun kendi amplifikatörü ile amplifiye edilen ses bilgisayar ortamına $44.1 \mathrm{kHz}$ örnekleme hızında kaydedildi. Ayrıca hastaların /a/ sesini kullanarak, piyano yardımı ile çıkabilecekleri maksimum ve minimum ses frekansları kayıt edildi. Toplanan bu kayitlardan online olarak bulunan Praat (Boersma, P\& Weenink, D, 2013, Version 5.2.21, www.praat.org) programı kullanılarak akustik analiz yapılmıştır. Bazal frekans (F0), jitter, shimmer, Harmonik-Gürültü oranı(H-to-N), hastaların seslerinin en tiz ve en pes frekansları ölçülmüştür. İki kayıt sonrasında istatistiksel olarak karşılaş̧ırılmıştır.

\section{İstatistik Analiz}

Normallik denetimi Shapiro Wilk testi, Histogram, Q-Q plot ve box plot grafikleri çizilerek yapıldı. Veriler medyan, minimum, maksimum, frekans ve yüzde şeklinde verildi. Pre-post karşılaş̧ırması Wilcoxon testi ile analiz edildi. Anlamlılık sınırı $p<0.05$ ve çift yönlü olarak alındı. Analizler NCSS 10 (2015. Kaysville, Utah, USA) yazılım programı kullanılarak yapıldı.
Tablo 1. Hastaların ses parametrelerinin karşılaştırılması

\begin{tabular}{lccc} 
& $\begin{array}{c}\text { Operasyon } \\
\text { öncesi }\end{array}$ & $\begin{array}{c}\text { Operasyon } \\
\text { sonrası }\end{array}$ & $\mathbf{p}$ \\
\hline Bazal frekans (F0) & 215.185000 & 209.142500 & .017 \\
Jitter & 0.349000 & 0.431500 & .326 \\
Shimmer & 3.451500 & 4.104000 & .317 \\
H-to-n & 17.943500 & 18.174500 & .232 \\
Maksimum frekans & 318.673500 & 308.630500 & .002 \\
Minimum frekans & 169.358500 & 151.254500 & .428 \\
Ses aralığı & 123.5040 & 104.4900 & .012 \\
\hline
\end{tabular}

\section{Bulgular}

Çalışmaya 40 hasta dahil edilmiştir. Hastaların 24'ü (\%60) kadın, 16'ı (\%40) erkekti. Hastaların yaş ortalaması 33.70 (17-55) idi. Tüm hastalar tek denemede entübe edildi. Operasyon süresi 1 saati geçmedi. Hastaların operasyon sonrasındaki Bazal Frekans (F0) değerlerinin, en tiz ses frekansının ve ses aralıklarının operasyon öncesi değerlere göre istatistiksel olarak anlamlı olarak daha az olduğu saptanmıştır. Jitter, Shimmer ve Harmonik-Gürültü Oranında ise anlamlı değişiklik saptanmamıştır (Tablo 1).

\section{Tartışma}

Ses solunum, kas-iskelet ve endokrin gibi birçok sistemin birbiri arasındaki uyumu ile oluşur ve kişiye özeldir. Akciğerlerden çıkan hava önce vokal kordları titreştirir, sonrasında üst hava yolunda işlenerek ağızdan çıkar. ${ }^{[6]}$ Bu yolculuk sırasındaki duraklardan birinde bir problem olursa ses kalitesinin bozulduğundan bahsederiz. Akciğer kapasitesinin değişimi, vokal kordlarda kitle, hasar ya da gerilim, üst hava yolunun darlıkları ses kalitesini direkt olarak etkilerler. ${ }^{[6]} \mathrm{EE}$ genel anestezi sırasında solunumu kontrol etmek ve anestezinin devamın sağlamak için 1900'lü yıllardan beri kullanılmaktadır. Bu işlem indüksiyon anestezisini takiben hastanın ağız içinden geçirilen ve trakea içine sabitlenen bir tüp ile yapılır. İnvaziv bir yöntem olması nedeni ile komplikasyona açıktır. Vokal korda kanama, kontakt ülserler, vokal proçes granülomu, vokal kord paralizisi, aritenoid dislokasyonu gibi mekanik travma sonucu gelişen hasarlar birçok yayında incelenmiştir. ${ }^{[3,4]}$ Bu görülebilen hasarların dışında birçok hasta ameliyat sırasında sesinin kısıldığını ya da yutma problemi yaşadığını bildirse de çoğu zaman bu şikayetler kısa süreli olması ve gözle görülebilen bir nedeni olmaması nedeni ile göz ardı edilmektedir.

Akustik ses analizi basit bir anlatım ile ses dalgalarının sayısal değerlere çevrilmesidir. Böylece ses dalgalarını evrensel bir dille inceleme, değerlendirme ve başkalarına anlatabilme imkanına sahip oluruz. Akustik ses analizi sırasında bazı parametreler tanımlanmıştır. Bunlar dan en sık Bazal Frekans (F0), Jitter, Shimmer ve Harmonik-Gürültü Oranı kullanılır. Bazal Frekans, bir saniye içinde meydana gelen glottik siklus sayısıdır. Jitter, her bir periyottaki frekans değişimini tarifler. Shimmer ise arka arkaya gelen periyotların arasında istem dışı olarak oluşan şiddet farklılıklarını gösterir. ${ }^{[7,8]}$ Harmonik-Gürültü Oranı (HNR), Harmonik 
ve temel seslerin gürültü enerjisine oranını ifade eder. Birimi $\mathrm{dB}$ olup yüksek değerler sesin daha sağlıklı olduğunu düşündürür. ${ }^{[8]}$ Glottik seviyede vokal kord hasarı sesin kalitesini dramatik şekilde değiştirebilir. Kullanılan inhalasyon anestezikleri ya da atropin gibi ilaçlar vokal kordların viskositesinin artmasına, dolayısıyla da vibrasyonun azalmasına neden olabilir. ${ }^{[5,9]}$ Bu çalışmada hasta grubunu seçerken sesin kalitesini etkileyebileceği için üst hava yolu cerrahisi geçiren, daha önce fonocerrahi operasyonu geçiren, toraks ya da abdominal cerrahi geçiren, sigara kullanan ve astım ya da koah gibi kronik hastalığı olan hastaları çalışmaya dahil etmedik. Ameliyat süresinin uzamasının da tübe bağlı lokal hasarı arttırması ve kullanılan ilaçların glottik seviyede striktürel değişikliklere neden olabilmesi nedeni ile ameliyatı 1 saati geçen hastaları araştırmaya dahil etmedik. Araştırma bu nedenlerle Amerikan Anestezi Topluluğu (ASA) kriterlerine göre 1. Evrede kabul edilen ve endotrakeal entübasyonunun bir kerede gerçekleştirildiği hastalar arasında yürütüldü.

Literatürde benzer çalışmaların yapıldığını görmekteyiz. Beckford ve ark.nın ${ }^{[5]}$ çalışmasında 10 hastanın pre ve postoperatif olarak incelendiği ve anlamlı değişiklik görülmediği bildirilmiştir. Hamdan'ın ${ }^{[6]}$ çalışmasında hastaların postoperatif 24 . saatte ses kısıklığı, ses yorulması, globus faringeus, boğaz temizleme ve boğaz ağrısı gibi şikayetlerinde artış olduğu ve Maksimum Fonasyon Zamanı (MFT)'nın azaldığını, ancak akustik analizde anlamlı bir değişikliğe ulaşamadıklarını bildirilmiştir. Yine benzer bir çalışmada çalışmaya dahil edilen 108 hastada şikayetlerin 24 saat sonrasında arttığı, MFT'nin azaldığı ve akustik parametrelerin arttığı gözlenmiştir. ${ }^{[10]} \mathrm{Bu}$ çalışmada yazarlar kullanılan tübün büyüklüğünün, tübün ucunda bulunan baIonun basıncının ve entübasyon sırasında birden fazla kez denenmesinin şikayetleri arttırdığını raporlamışlardı. ${ }^{[10]}$

Çalışmanın verileri incelendiğinde hastaların Bazal Frekans (F0), en tiz frekans olarak ölçülen Maksimum frekans değerinde ve hastaların ses aralığında istatistiksel olarak azalma saptanmıştır. Biz bu sonucu, endotrakeal tübün direkt ve kullanılan ilaçların endirekt olarak vokal kordların kütlesini arttırmasına ve vibrasyon kapasitesini azaltmasına bağladık. Jitter, Shimmer, Harmonik-Gürültü oranı ve minimum frekans değerlerindeki değişimde ise anlamlı bir fark saptanmamıştır. Bu veriler daha çok mukozal dalgalanmayı incelemektedir. Bu sonuçlarla kısa süreli operasyonlarda mukozal dalganın çok etkilenmediği sonucuna varabiliriz. Mukozal dalgaların incelenmesinde daha uzun süreli operasyonlarda benzer çalışmaların yapılması kanaatindeyiz.

Bu çalışmada hastaların ses aralığının nasıl etkilendiğini de inceledik. Bu ölçümdeki amacımız daha çok sesini kullanarak geçimini sağlayan kişilerin entübasyon sonrasında sesini hangi düzeyde kullanabileceklerini öğrenmekti. Hastaların ses aralığının anlamlı olarak azaldığını saptadık. Bu nedenle kısa süreli de olsa opere olan ve EE yapılan kişilerin operasyon sonrasında seslerini bir süre kullanmamalarını tavsiye etmekteyiz. Bu çalışmanın bazı kısıtlamaları olmuştur. Öncelikle çalışmaya ses parametrelerini değiştireceği düşünülerek üst hava yolu, tiroid, toraks ya da abdominal cerrahi geçiren hastaları dahil et- medik. Aynı şeklide daha önce ses cerrahisi yapılan hastalar da çalışmaya alınmadı. Ameliyat öncesinde EE sırasında birden fazla girişim yapılan ve ameliyatı 1 saatten uzun süren hastalar da bu çalışma grubuna alınmadı. Böylece hastalar arasında uygun bir standardizasyon sağladığımızı düşünmekteyiz. Ancak bu tutum hasta sayısını belli bir sayıda kalmasına neden olmuştur. Ayrıca mukozal dalgalanmanın parametrelerinde belli bir sonuca ulaşamadık. Bu nedenle hasta sayısının daha fazla olduğu ya da ameliyat süresinin daha uzun tutulduğu bir çalışmanın da yapılabileceği ve bilgilerimize ışık tutabileceğini düşünüyoruz.

\section{Sonuç}

EE'un invaziv bir griişim olması nedeni ile vokal kordlar üzerinde belli etkileri olmaktadır. Bu etkilerin kısa sürede gerilemesi nedeni ile cerrahlar tarafından çok önemsenmemektedir. Ancak ses profesyonelleri diye adlandırılan grupta bu etkiler çok önemli olabilir. Bu nedenle özellikle ses profesyonellerinin operasyon sonrasında geçici bir süre için seslerini eskisi gibi kullanamayacakları hastalara bildirilmelidir.

Çıkar çatışması: Bildirilmemiştir.

\section{Kaynaklar}

1. Brandt L. The history of endotracheal anesthesia, with special regard to the development of the endotracheal tube. Anaesthesist 1986;35:523-30.

2. Atkinson RS, Rushman GB, Davies NJH (editors). Lee's synopsis of anaesthesia. ELBS with Butterworth-Heinemann, Oxford: 1993. p. 217-38.

3. Ward PH, Zwitman D, Hanson D, Berci G. Contact ulcers and granulomas of the larynx: new insights into their etiology as a basis for more rational treatment. Otolaryngol Head Neck Surg (1979). 1980;88:262-9.

4. Hahn FW Jr, Martin JT, Lillie JC. Vocal-cord paralysis with endotracheal intubation. Arch Otolaryngol 1970;92:226-9.

5. Beckford NS, Mayo R, Wilkinson A 3rd, Tierney M. Effects of shortterm endotracheal intubation on vocal function. Laryngoscope 1990;100:331-6.

6. Hamdan AL, Sibai A, Rameh C, Kanazeh G. Short-term effects of endotracheal intubation on voice. J Voice 2007;21:762-8. Epub 2006 Aug 14. PMID: 16905292.

7. Woodson GE, Cannito M. Voice analysis. In Cummings CW And Others (Eds). Otolaryngology Head And Neck Surgery. Third Edition, Missoury, Mosbyyear book Inc 1998;1876-90.

8. Stemple C.S. Leslie E.G. Clinical Voice Pathology Theory and Management, Third Ed. Singular Publishing Group, Canada 2000;423.

9. Finkelhor BK, Titze IR, Durham PL. The effect of viscosity changes in the vocal folds on the range of oscillation. JVoice 1988;1:320-5.

10. Paulauskiene, Lesinskas E, Petrulionis M. Eur Arch Otorhinolaryngol. The temporary effect of short-term endotracheal intubation on vocal function. 2013;270:205-10. doi: 10.1007/s00405-0122130-4. Epub 2012 Aug 3. 